\title{
Effect of Temperature on the Performance of Photovoltaic Module
}

\author{
Muhammad Sani \\ Physics Unit \\ Department of Sciences \\ State College of Basic and Remedial Studies, Sokoto \\ Nigeria
}

\begin{abstract}
Metrological parameters plays significant role on the performance of solar panels in electrical power generation. To ascertain the extent to which ambient temperature, temperature of the panels, solar radiation were measured, recorded and analyzed at half-hour interval for five days, at the same period two solar panels were subjected to test, one being connected to a system of cooling leaving the other untouched. Measurement of both the output current and voltage were made from which the power output was calculated. The result shows that the power output was increasing as the solar radiation increased, which is clear indication that the entire photovoltaic process depend on the radiation intensity and environmental conditions. It was also observed that the efficiency of the solar panel with cooling system is slightly greater than that without cooling system. The efficiency and energy output of both solar panels were determined to be $15 \%$, $13 \%$ and $477 \mathrm{kWh}, 449 \mathrm{kWh}$ respectively. The difference of $28 \mathrm{kWh}$ is not supposed to be neglected, because considering the difference of many days and many panels cannot be neglected. Also few approaches that have been proposed to reduce the effect of temperature on the solar photovoltaic system by choosing the appropriate configurations, by mounted on free standing frames, photovoltaic thermal collectors and building integrated photovoltaic arrays, respectively.
\end{abstract}

\section{INTRODUCTION}

The demand for electricity to meet the need of the society is increasing in Nigeria. To meet this need, many Nigerians are now seeking alternative source of energy besides the rapidly deflecting and polluting fossil fuels that the current infrastructure has become dependent upon.

The use of solar energy to meet residential energy needs has been promoted for some years in Nigeria by some renewable energy companies, Olorummai, (2012). This was due to the numerous advantages that the solar energy is the energy produced directly by the sun in form of radiation, and captured on the earth for practical ends for generating electricity.

Solar energy can be converted into electricity directly using photovoltaic (PV) solar module which converts sunlight into electricity using photoelectric effect, Fthenakis, and Kim, (2009).

\author{
Abdulmumin Sule \\ Physics Unit \\ Department of Sciences \\ State College of Basic and Remedial Studies, Sokoto \\ Nigeria
}

Photovoltaic system is a power generation system designed to use solar energy and produced electricity by means of photoelectric effect. It consist of arrangement of several components, including solar panels to absorb and directly convert sunlight into electricity, a solar inverter is used to convert alternating current (AC) into direct current (DC), a battery bank also store energy and a charge controller to regulate the battery voltage as well as mounting, cabling, and other electrical accessories to set-up a working system, Fthenakis and Kim, (2009). However, the solar photovoltaic system strongly depends on the solar radiation intensity. And only $15 \%$ of sun radiation is converted into electricity with the rest converted into heat. The electrical efficiency will decrease when the operating temperature of the PV module increases. Photovoltaic devices are typically sold on the basis of standard test condition efficiency. This is not necessary a good measure for the realistic energy production. Jardine et al, (2001).

\section{$>$ Renewable Energy}

Renewable energy sources, also called nonconventional energy, are sources of energy that are continuously replenished by natural processes. For example, solar energy, wind energy, bio-energy, hydropower plants, geothermal energy, wave and tidal energy are example of renewable energy sources, Fthenakis and Kim, (2009).

A renewable energy system converts the energy found in sunlight, wind, falling-water, sea-wave, geothermal heat and biomass into a form, we can use such as heat or electricity. Most of the renewable energy comes either directly or indirectly from sun and wind which can never be exhausted, and therefore they are called renewable, Fthenakis and Kim, (2009).

\section{Solar Radiation}

Solar radiation is the radiation, or energy we get from sun. It is also known as short wave radiation. Solar radiation comes in many ways such as visible light, radio waves, heat (infrared), X-rays and Ultraviolet rays. Measurements of solar radiation are higher on clear sunny days and usually low on cloudy days. When the sun is down or there are heavy cloudy blocking the solar radiation is measured at zero Bailey and Robert, (2008). 
Solar radiation is the total frequency spectrum of electromagnetic radiation produced by the sun. This spectrum covers visible light and near visible radiation, such as X-rays, ultraviolet, infrared radiation and radio waves. Also solar radiation is radiant energy emitted by the sun, particularly electromagnetic energy Bailey and Robert ,(2008).

\section{$>$ Component Of Solar Radiation}

- Direct solar radiation: it also called "Direct Beam radiation" it is used to describe solar radiation traveling on a straight line from the sun down to the surface of the earth, Bailey and Robert, (2008).

- Diffuse solar radiation: diffuse solar radiation describes the sunlight that has been scattered by air molecules and particle in the atmosphere such as aerosol and still made it down to the surface of the earth, Bailey and Robert, (2008).

\section{$>$ Heat And Temperature}

Heat and temperature easy to observe but are rather difficult to describe and fully understood. For example, in solar heating field we typically speak of strong heat and stored heat, but thermodynamically heat cannot be stored. Rather heat is an interaction and classes to exist once an energy-transfer process stops.

Temperature is not a measure of energy, but the temperature of an object is related to the amount of motion energy an average molecule has. The faster the average molecule is moving the higher the temperature of the object. This means that in some ways the temperature of an object is related to how much internal energy the object contains, since both temperature and internal energy are related to motion energy. But temperature is average "average" energy and internal energy is total energy, Bashir and Sambo, (1999).

\section{Efficiency Of The Solar Cell}

Solar cell efficiency is the ratio of the electrical output of a solar cell to the incident energy in the form of sunlight. The energy conversion (n) of a solar cell is the percentage of the solar energy to which the solar cell is expose that is converted into electrical energy. Efficiency is calculated by dividing s cell's power output (in watt) at its maximum power point $(\mathrm{Pm})$ by the input light $(\mathrm{E}$, in $\mathrm{W} / \mathrm{m} 2)$ and the surface area of the solar cell (Ac in $\mathrm{m} 2$ ).

$\eta=$ Pm/E.A.

Where $\mathrm{n}$ is the energy conversion efficiency, $\mathrm{Pm}$ is the maximum power point, $\mathrm{E}$ is the input light, and $\mathrm{A}$ is the surface area of the solar cell.

\section{$>$ Fill Factor $(F f)$}

The fill factor (FF) is essentially a measuring of the quality of solar cell. It is calculated by comparing the maximum power to the theoretical power (PT) that would be output at both the open circuit voltage and short circuit current where:

$\mathrm{FF}=\operatorname{Pmax} / \mathrm{P}_{\mathrm{T}}=\operatorname{Imp} . \mathrm{V}_{\mathrm{MP}} / \mathrm{I}_{\mathrm{SC}} \cdot \mathrm{Voc}=$ Imp.vmp/Isc. Vo. ...ii

\section{$>$ Thermodynamics Of The System}

Thermodynamics is the branch of natural science concern with heat and its relation to other forms of energy and work. Thermodynamics is the study of amount of energy moving in and out of the systems.

The thermodynamics in the process of water cooling of solar cell in this paper is water in the tank flows from the tank down through the PVC pipes to copper pipe beneath the solar panel, at certain time when the solar panel gets hot, the water start to absorb some amount of heat from the solar panel which tends to reduce some amount of heat absorbed by the panel to the copper pipe, and from the copper pipe to the water tank, which makes the water becomes hot and start to rise up. Because denser water goes up while the less denser comes down to the pipe, the process is continuous with the hot water coming back to the tank as a continuous process.

$\mathrm{DU}=\mathrm{DQ}+$

DW....

$\mathrm{Q}$ is the charge

$\mathrm{U}$ is the internal energy and

$\mathrm{W}$ is the work done.

Photovoltaic (PV) is a method of generating electrical power by converting solar radiation into direct current electricity using a solar cell $\mathrm{p}-\mathrm{n}$ junction semiconductors that produces the photoelectric effect. It is not the heat required from the sun but the amount of irradiation available (Aldo Vieira Da Rosa, 2005).

\section{$>$ Photoelectric Effect}

The photoelectric effect was first noted by a French physicist, Edmund Bequerel, in (1839), who found that certain materials would produce small amounts of electrical current when exposed to light. The theory of the solar cell is the solar effect of semiconductor material. The solar effect is a phenomenon that the semiconductor material absorbs the solar energy, and then the electron-hole excited by the photon separates and produces electromotive force.

\section{$>$ Photovoltaic Cell}

The basic unit of a photovoltaic system is (PV) cell also called solar cell. It is a semiconductor device that can convert sunlight into direct electrical current (DC). When sunlight shines on PV/solar cell, it may be reflected, absorbed or passed through. But only the absorbed sunlight generates electricity Aldo Vieira Da Rosa, (2005). 


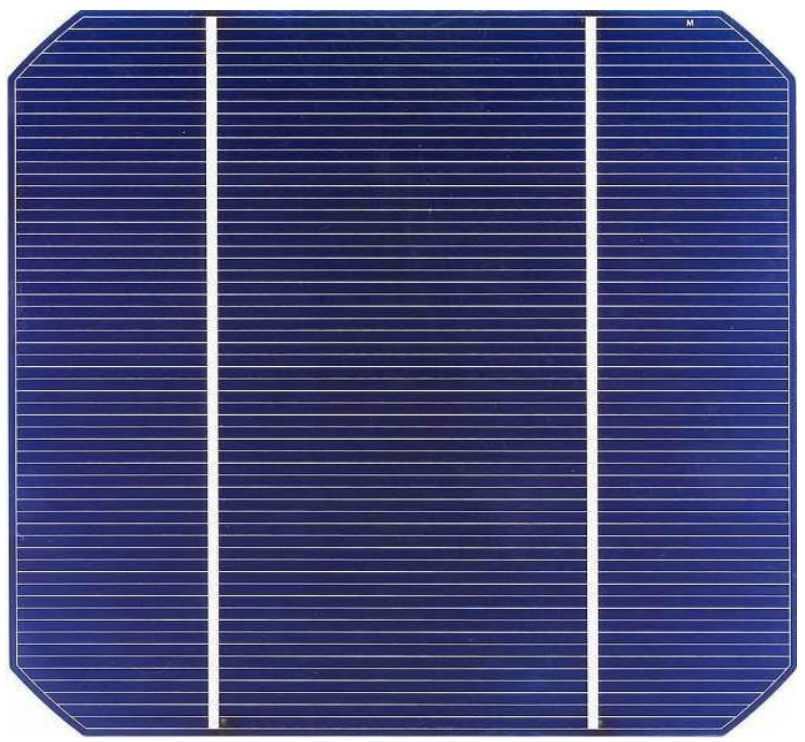

Fig 1:- A Solar Photovoltaic Cell

(Http://org.ntnu.no/solarcell/pages/hiztory.php)

A solar cell also called photovoltaic cell is a semiconductor $\mathrm{p}-\mathrm{n}$ junction device, a semiconductor $\mathrm{p}-\mathrm{n}$ junction is form when a crystal of p-type material are brought into conjunction with the crystal of n-type material such that the junction represent perfect continuation of the lattice even in the unexcited state, i.e. all subatomic particle are in constant motion due to thermal energy, as such that any increase in temperature causes the release of further electrons and holes due breaking of covalent bond.

\section{Effect Of Temperature On The Performance Of Photovoltaic Module}

Like all other semiconductor devices, solar cells are sensitive to temperature. Increase in temperature reduce the band gap of a semiconductor, thereby effecting most of the semiconductor material parameters. The decrease in the band gap of a semiconductor with increasing temperature can be viewed as increasing the energy of the electron in the material. Lower energy is therefore needed to break the bond in the bond model of a semiconductor. Therefore increase in temperature reduce the band gap in a solar cell, the parameter most affected by an increase in temperature is the open-circuit voltage. Thus this reduced the output power and the efficiency of photovoltaic module.

\section{$>$ Experimental Methods}

The experimental setup was designed to investigate how temperature affects the output power and efficiency of PV panels during operation. Two $160 \mathrm{~W}$ polycrystalline solar modules were used in the experiment to determine the open circuit voltage (voc) and the short circuit current (isc) of the two polycrystalline solar panels. With one of the PV having water cooling system under and other has no cooling system in other to know how temperature affects both of them. An array of copper pipes that allow the water to flow through was attached underneath one of the PV module, the pipes were welded in such a way there is no any leakage of water within the pipes.

A continuous flow of water occur in this experiment, where the PVC pipes were connected from the water tank by the use of elbow and sockets to the copper pipes which are underneath the solar panel. The experiments were conducted from 8:00am to 5:00pm for five days. A Pyranometer was used to capture global solar irradiance. Temperature measurements are important in this experiment and therefore calibrated T-type thermocouples were utilized. In the experiment, PV current, PV voltage, temperature of the two panels, temperature of the pipes, temperature of water in the tank, ambient temperature, wind speed, and solar irradiance were collected.

\begin{tabular}{|lc|}
\hline Parameter & value \\
Maximum power (PM) & $160 \mathrm{~W}$ \\
Maximum power voltage (vmp) & $36.663 \mathrm{~V}$ \\
Maximum power current (Imp) & $4.370 \mathrm{~A}$ \\
Open circuit voltage (voc) & $44.322 \mathrm{~V}$ \\
Short circuit current (Isc) & $4.677 \mathrm{~A}$ \\
Maximum system operating voltage (v) & $1000 \mathrm{~V}$ \\
Fuse series rating & $15 \mathrm{~A}$ \\
Cell technology & Poly-Si \\
Application class & Class A \\
Standard test condition (stc) & 25, C, 1.5Am, 1000W/M2 \\
\hline
\end{tabular}

Table 1:- Electrical Characteristics of PV Module 


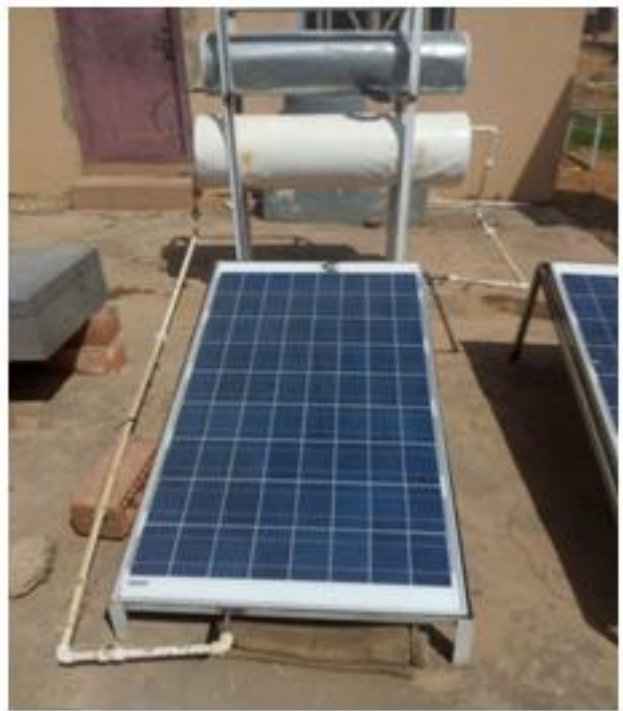

PV with cooling system

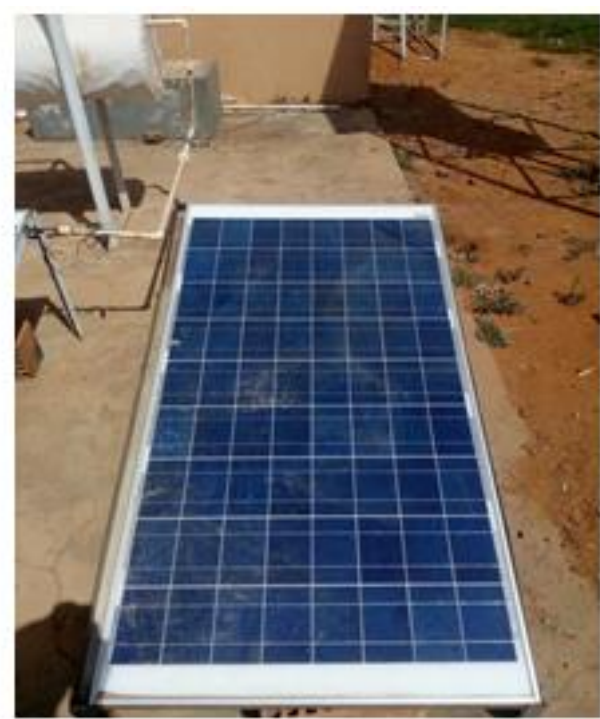

PV without cooling system

Fig 2:- 160W polycrystalline PV modul

\section{RESULT AND DISCUSSION}

The average result for various temperature such as temperature of water tank $\left(\mathrm{T}_{\mathrm{WT}}\right)$, temperature of the copper pipe (Tc), Ambient temperature $\left(\mathrm{T}_{\mathrm{A}}\right)$, temperature of PV with cooling system (Tpc) and temperature of PV without cooling system (Tpw), solar radiation and open circuit voltage, short circuit current for five days which started from 8:00am-5:00pm daily was recorded and the output power and efficiency for both modules was also calculated as shown in the Table 2 and 3 below.

\begin{tabular}{|c|c|c|c|c|c|}
\hline \multicolumn{6}{|c|}{ Average of various Temperatures } \\
\hline TIME & $\mathrm{T}_{\mathrm{PW}}$ & $\mathrm{T}_{\mathrm{PC}}$ & $\mathrm{T}_{\mathrm{A}}$ & $\mathrm{T}_{\mathrm{C}}$ & $\mathrm{T}_{\mathrm{WT}}$ \\
\hline 8:00am & 30.10 & 29.30 & 28.5 & 26.16 & 23.20 \\
\hline 8:30am & 34.27 & 31.37 & 36.36 & 27.60 & 24.10 \\
\hline 9:00am & 38.27 & 39.67 & 40.77 & 35.73 & 26.63 \\
\hline 9:30am & 41.13 & 45.13 & 45.43 & 38.87 & 27.33 \\
\hline 10:00am & 46.43 & 47.67 & 46.90 & 43.23 & 30.43 \\
\hline 10:30am & 49.80 & 48.27 & 44.0 & 44.67 & 31.30 \\
\hline 11:00am & 52.70 & 52.47 & 47.27 & 45.53 & 32.50 \\
\hline 11:30am & 55.06 & 52.53 & 50.87 & 48.47 & 34.23 \\
\hline 12:00pm & 56.40 & 51.51 & 53.90 & 51.0 & 35.20 \\
\hline $12: 30 \mathrm{pm}$ & 57.97 & 47.57 & 51.30 & 51.80 & 36.60 \\
\hline 1:00pm & 57.53 & 51.33 & 40.40 & 52.47 & 37.10 \\
\hline $1: 30 \mathrm{pm}$ & 58.43 & 54.23 & 44.90 & 49.43 & 38.13 \\
\hline 2:00pm & 58.10 & 50.30 & 48.47 & 50.67 & 38.93 \\
\hline $2: 30 \mathrm{pm}$ & 63.70 & 46.33 & 52.63 & 50.53 & 38.73 \\
\hline 3:00pm & 50.57 & 43.13 & 46.27 & 49.60 & 40.0 \\
\hline 3:30pm & 45.23 & 40.0 & 39.0 & 44.37 & 39.67 \\
\hline 4:00pm & 42.90 & 34.30 & 36.87 & 42.30 & 38.20 \\
\hline $4: 30 \mathrm{pm}$ & 38.47 & 33.20 & 36.53 & 36.70 & 36.70 \\
\hline 5:00pm & 35.97 & 33.57 & 36.27 & 36.50 & 35.83 \\
\hline
\end{tabular}

Table 2:- Average values for various temperatures 


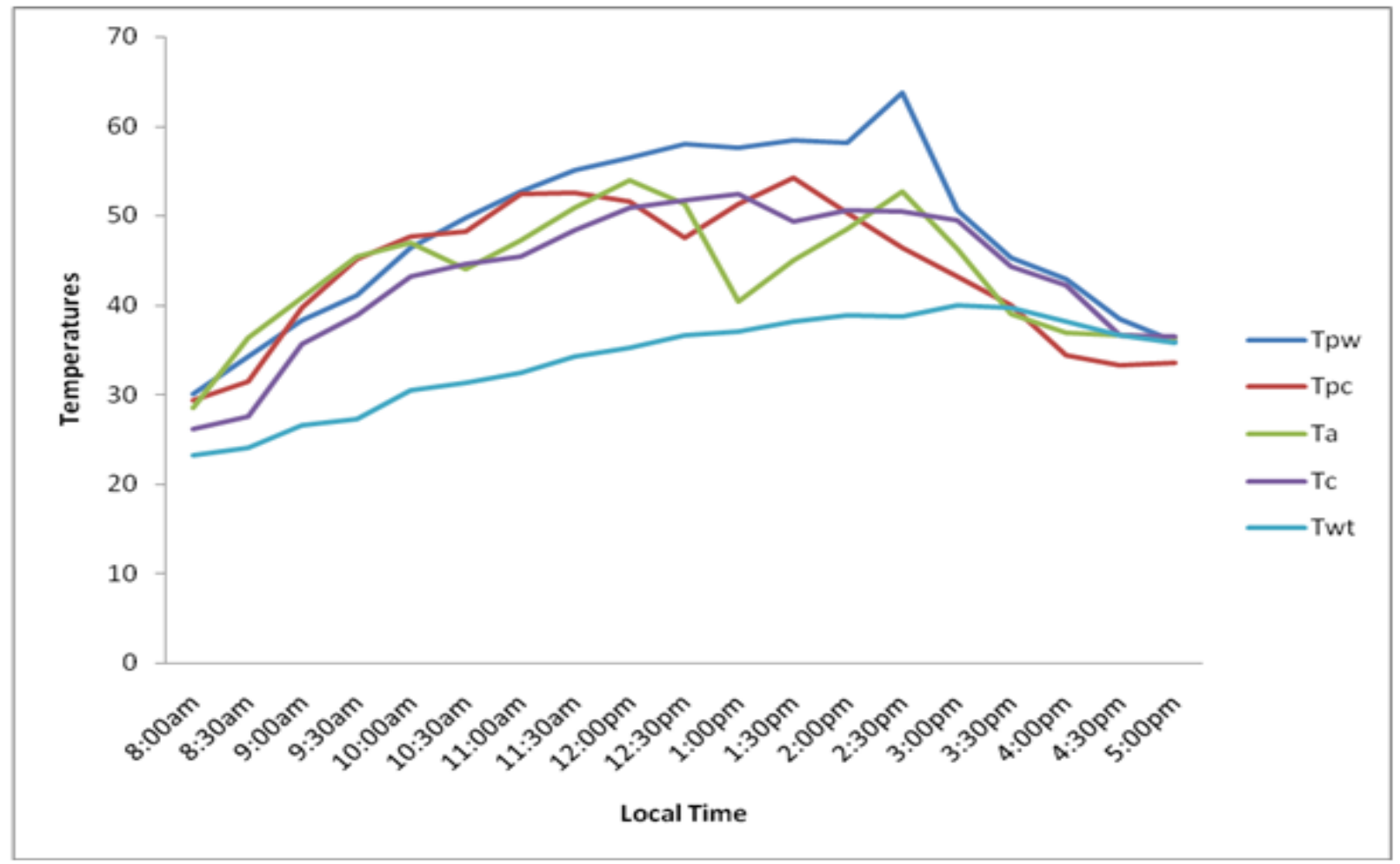

Fig 3:- Graph of various temperature against local time

\begin{tabular}{|c|c|c|c|c|c|c|c|c|c|}
\hline Time & $\begin{array}{c}\text { Solar } \\
\text { rad.(E) }\end{array}$ & $\mathrm{V}_{1}$ & $\mathrm{~V}_{2}$ & $\mathrm{I}_{1}$ & $\mathrm{I}_{2}$ & $\mathrm{P}_{1}$ & $\mathrm{P}_{2}$ & $\eta_{1}$ & $\eta_{2}$ \\
\hline 8:00am & 336 & 27.20 & 24.24 & 1.31 & 2.08 & 62.83 & 50.41 & 0.09 & 0.12 \\
\hline 8:30am & 386 & 28.35 & 25.18 & 1.85 & 2.95 & 75.41 & 74.28 & 0.10 & 0.15 \\
\hline 9:00am & 513 & 32.41 & 31.82 & 3.04 & 3.95 & 98.52 & 125.69 & 0.16 & 0.19 \\
\hline 9:30am & 685 & 33.42 & 33.35 & 3.39 & 3.34 & 146.71 & 111.39 & 0.17 & 0.18 \\
\hline 10:00am & 643 & 34.32 & 33.56 & 4.74 & 3.97 & 162.68 & 133.23 & 0.18 & 0.18 \\
\hline $10: 30 \mathrm{am}$ & 737 & 34.49 & 34.38 & 4.18 & 4.79 & 171.16 & 164.58 & 0.19 & 0.18 \\
\hline 11:00am & 801 & 36.80 & 34.71 & 4.06 & 4.07 & 149.40 & 141.27 & 0.19 & 0.17 \\
\hline 11:30am & 848 & 36.41 & 34.16 & 4.38 & 4.06 & 159.48 & 138.69 & 0.20 & 0.17 \\
\hline $12: 00 \mathrm{pm}$ & 902 & 36.84 & 32.72 & 4.31 & 4.98 & 177.20 & 162.94 & 0.20 & 0.16 \\
\hline $12: 30 \mathrm{pm}$ & 953 & 34.80 & 33.34 & 4.96 & 5.06 & 172.60 & 168.70 & 0.19 & 0.16 \\
\hline 1:00pm & 999 & 36.45 & 32.48 & 5.01 & 5.27 & 182.61 & 171.16 & 0.19 & 0.15 \\
\hline $1: 30 \mathrm{pm}$ & 991 & 36.45 & 29.45 & 4.38 & 6.33 & 195.94 & 186.42 & 0.18 & 0.15 \\
\hline $2: 00 \mathrm{pm}$ & 879 & 36.06 & 28.80 & 4.13 & 5.80 & 148.93 & 167.04 & 0.18 & 0.14 \\
\hline $2: 30 \mathrm{pm}$ & 805 & 35.18 & 20.15 & 3.43 & 5.50 & 155.84 & 110.82 & 0.17 & 0.13 \\
\hline 3:00pm & 715 & 33.79 & 29.36 & 3.68 & 3.87 & 124.34 & 113.62 & 0.15 & 0.13 \\
\hline 3:30pm & 558 & 35.18 & 32.57 & 2.79 & 2.89 & 90.75 & 94.13 & 0.13 & 0.13 \\
\hline $4: 00 \mathrm{pm}$ & 389 & 33.53 & 39.52 & 0.68 & 0.86 & 50.86 & 94.05 & 0.12 & 0.12 \\
\hline $4: 30 \mathrm{pm}$ & 253 & 32.56 & 29.76 & 0.57 & 0.73 & 17.42 & 21.73 & 0.09 & 0.06 \\
\hline $5: 00 \mathrm{pm}$ & 176 & 29.58 & 28.199 & 0.50 & 0.55 & 14.79 & 15.50 & 0.05 & 0.05 \\
\hline
\end{tabular}

Table 3:- Result for Average Solar Radiation (E), Electrical parameters and Efficiencies 


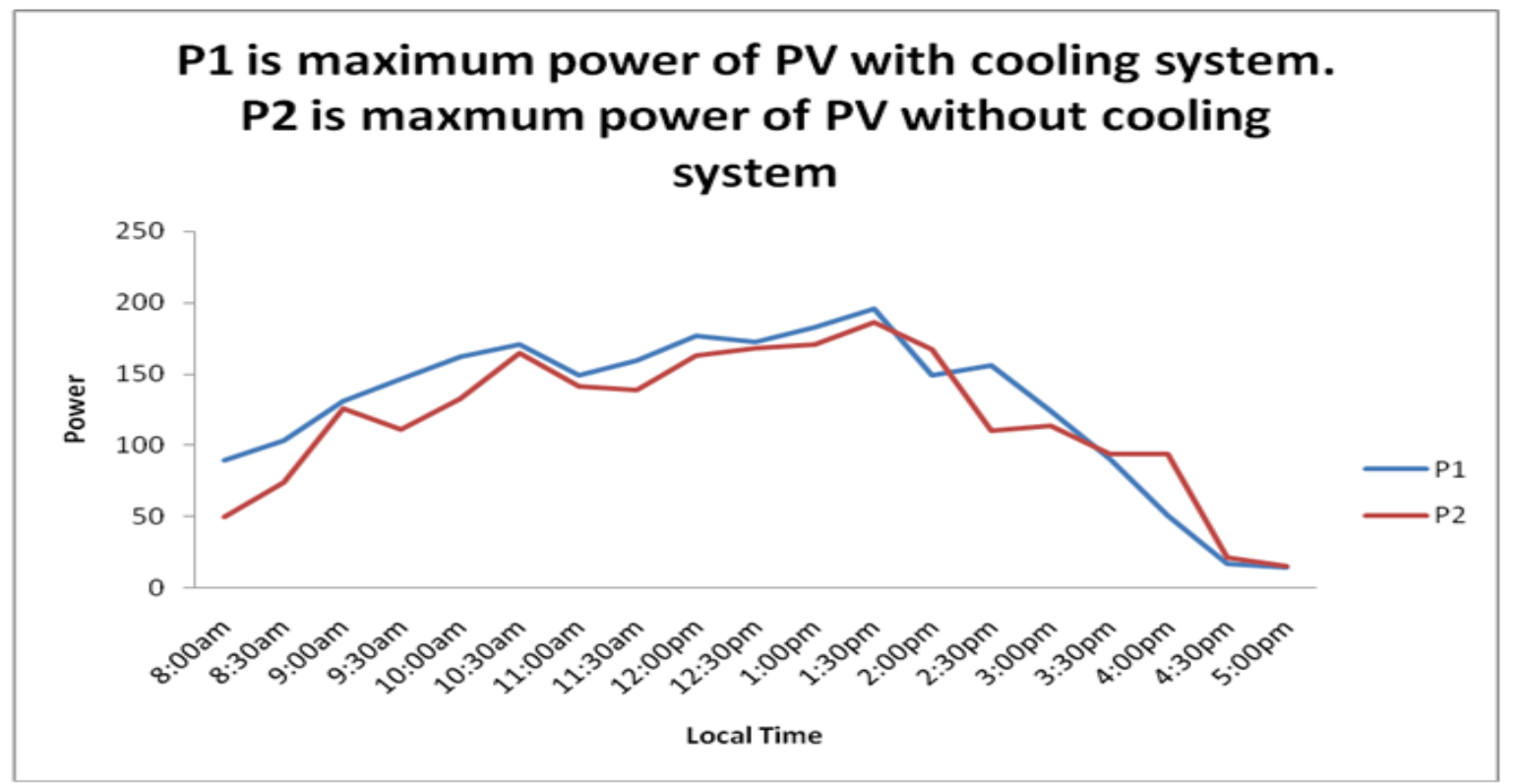

Fig 4:- Graph of power against local time

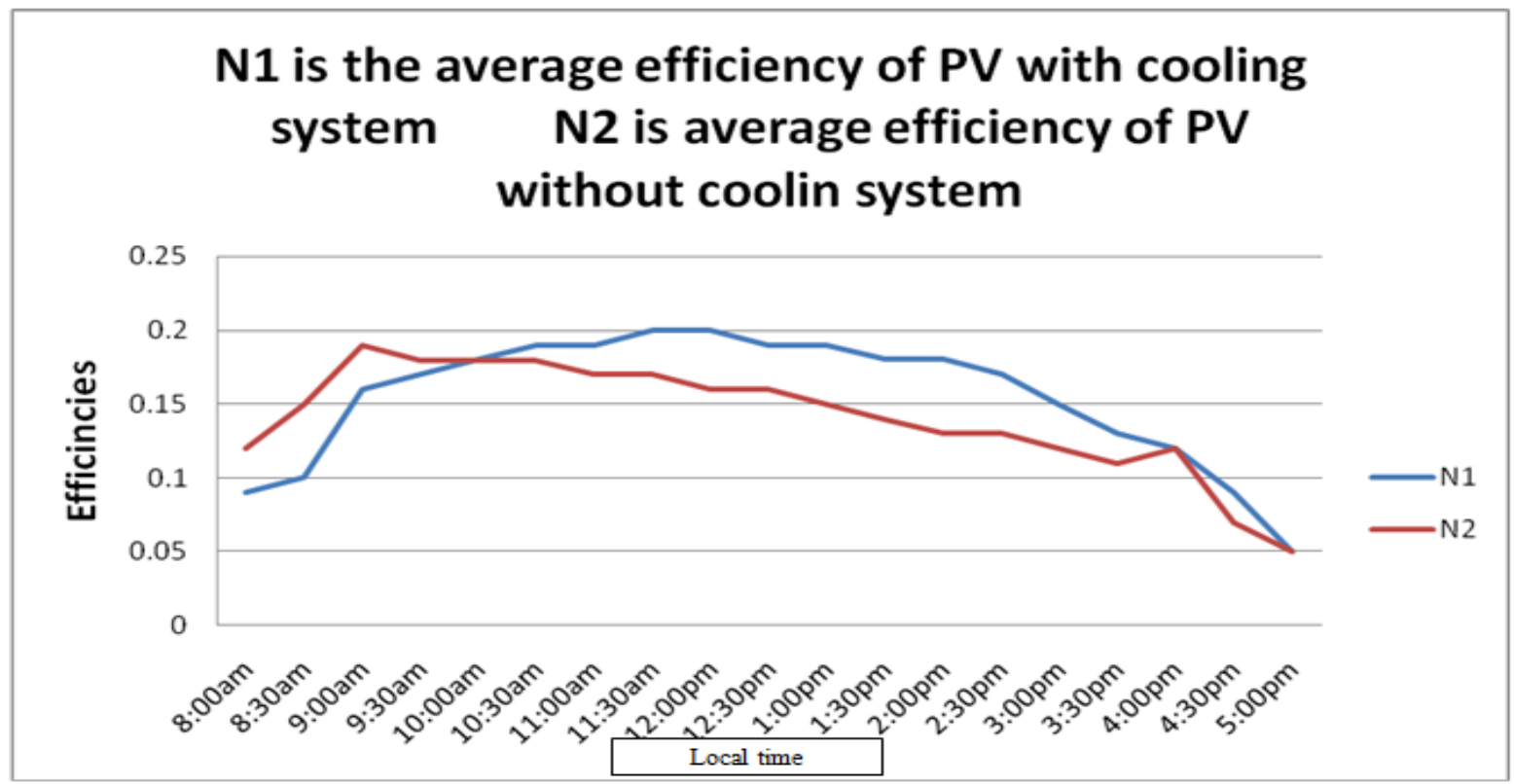

Fig 5:- Graph of efficiencies against local time

The length of the panel was measured using meter tape as $118.7 \mathrm{~cm}=1.187 \mathrm{~m}$; and the breadth was measured to be equal to $104 \mathrm{~cm}=1.04 \mathrm{~m}$

The area of the panel is given by:

$A=L \times B$.

Where

A is the area of the panel

$\mathrm{L}$ is the length of the panel

$B$ is the breadth of the panel

Substituting the values gives

Area, $\mathrm{A}=1.187 \mathrm{~m} \times 1.04 \mathrm{~m}=1.24 \mathrm{~m}^{2}$

The power output is given by

$\mathrm{P}_{\text {out }}$

\section{iv}

$=$
While the power input is:

$P_{\text {in }}$ $=$

E

$\times$

A vi

Where

$\mathrm{I}=$ Current

$\mathrm{V}=$ Voltage

$\mathrm{E}=$ Solar radiation

$\mathrm{A}=$ Area of the module

Therefore the efficiencies of the two panels are calculated using:

$\mathrm{D}=\quad \mathrm{P}_{\mathrm{OUT}} / \mathrm{P}_{\mathrm{IN}} \quad=\quad \mathrm{I} \times \mathrm{V} / \mathrm{E} \times \mathrm{A}$ 


\section{CONCLUSIONS}

This paper present the effects of temperature on the performance of photovoltaic module and proved that the output power of photovoltaic module mainly depends on solar radiation intensity and environmental conditions which clearly indicated that the output power of PV module with cooling system is slightly greater than the PV module without cooling system whereby current increases with increase in temperature and the output voltage decreases with increase in temperature which negatively affect the output power and the efficiency of photovoltaic module. It was also noted that any increase in temperature by one degree Celsius result in decrease of voltage by $0.12 \mathrm{~V}$ which negatively affect the output power and overall performance of photovoltaic system.

From the table 3 and Figure 4 it can be seen that the data and graph plotted of photovoltaic module power with cooling system $\left(\mathrm{P}_{1}\right)$ and module without cooling system $\left(\mathrm{P}_{2}\right)$ against time which in which the maximum out power was attain at $1: 30 \mathrm{pm}$ for both modules. It was also clearly noted that the output power of module with water cooling system slightly greater than the module without water cooling system which is to about $195.94 \mathrm{~W}$ and $186.42 \mathrm{~W}$ respectively.

The efficiencies and energy output of both solar panels were determined to be $15 \%, 13 \%$ and $477 \mathrm{kWh}$, $449 \mathrm{kWh}$ respectively. The difference of $28 \mathrm{kWh}$ is not supposed to be neglected, because considering the difference of many days and many panels cannot be neglected.

There are also few approaches that have been proposed to reduce the effect of temperature on the solar photovoltaic system by choosing the appropriate configurations, by mounted on free standing frames, photovoltaic thermal collectors and building integrated photovoltaic arrays, respectively.

\section{RECOMMENDATIONS}

The experiment was perform during end in summer period (June), it is also recommended to be repeated during early summer and in winter period to compare the result.

$>$ The angle in which the module was mounted is about $60^{\circ} \mathrm{S}$, it is recommended to repeat the experiment by using latitude of sokoto (about $30^{\circ} \mathrm{N}$ ).

$>$ The experiment was conducted as an open system, it is recommended to conduct it again as close system (by connecting load).

In the experiment only $160 \mathrm{~W}$ polycrystalline modules were used, it also recommended to use different varieties of module to compare the performance.

$>$ It is also recommended to redesign the system so that it provides hot water for domestic use and at same time as coolant.

\section{REFERENCES}

[1]. Aldo Vieira Da Rosa. (2005):"Fundamentals of renewable energy processes," Elsevier Academic press:pp 85, 88, 95-96.

[2]. Becquerel, A. E. (1839). Comt. Rend Acad. Sci 9561.

[3]. Bailey, J.and Robert L, (2008): "Basic photovoltaic principles and methods." Ann arbor, MI: Ann Arbor science: pp 55, 58, 60-65.

[4]. Bashir, G., and Sambo, A. S. (1999). Solar energy option. Sokoto, Usmanu Danfodiyo university press.

[5]. Fthenakis, V. and Kim, H.C. (2009): "Land use and electricity generation: A life-cycle analysis" peaeson: pp 45-48.

[6]. Jardine, C., Coniber, G.J., and Lane, A. (2001). "PV COMPARE: Direct comparism of PV".

[7]. James, A.F. and Golombs, D. S. (2005): "Energy and environment" Hot Rinehart and winson: pp 147-150.

[8]. Nguyen, D.D and Sagar, K. (2009): "Performance evaluation of solar photovoltaic arrays including shadow effects using neural network" moderm applied science: pp 95-101.

[9]. Olorummai J. (2012): "Energy commission of Nigeria on occasions of training in Nigeria's industry" renewable energy development 3(4): pp 34-37.

[10]. Http://org.ntnu.no/solarcell/pages/hiztory.php 